BMJ

Open

Gastroenterology

\title{
Changes in metabolic complications in patients with alcoholic fatty liver disease monitored over two decades: NAGALA study
}

\author{
Masahide Hamaguchi (D) , ${ }^{1}$ Akihiro Obora, ${ }^{2}$ Takuro Okamura (D) ,1 \\ Yoshitaka Hashimoto, ${ }^{1}$ Takao Kojima, ${ }^{2}$ Michiaki Fukui ${ }^{1}$
}

To cite: Hamaguchi M, Obora A, Okamura T, et al. Changes in metabolic complications in patients with alcoholic fatty liver disease monitored over two decades: NAGALA study. BMJ Open Gastro 2020;7:e000359. doi:10.1136/ bmjgast-2019-000359

- Additional material is published online only. To view, please visit the journal online (http://dx.doi.org/10.1136/ bmjgast-2019-000359).

Received 10 December 2019 Revised 5 March 2020 Accepted 12 March 2020

Check for updates

(c) Author(s) (or their employer(s)) 2020. Re-use permitted under CC BY-NC. No commercial re-use. See rights and permissions. Published by BMJ.

${ }^{1}$ Endocrinology and Metabolism, Graduate School of Medical Science, Kyoto Prefectural University of Medicine, Kyoto, Japan

${ }^{2}$ Gastroenterology, Asahi University Hospital, Gifu, Japan

Correspondence to Dr Masahide Hamaguchi; mhama@koto.kpu-m.ac.jp

\section{ABSTRACT}

Objective The social conditions are changing in the world, which may contribute to the change in lifestyle, including alcohol consumption and dietary intake; however, changes in metabolic complications in patients with alcoholic fatty liver disease (AFLD) have never been reported. Therefore, here we compare the metabolic complications in current AFLD with those of two decades ago.

Methods We performed this cross-sectional study in a Japanese health check-up centre. Consecutive participants who visited the facilities between June 1994 and December 1997 or between January 2014 and December 2017 were enrolled. A total of 7499 participants (4804 men, 2695 women) in the past cohort and 20029 participants (11676 men, 8353 women) in the current cohort were entered to this study.

Results The prevalence of drinkers in the current cohort was significantly lower (4.7\%) than that in the past cohort in men $(5.9 \%, p<0.001)$ but significantly higher in women $(1.9 \%$ in the current vs $1.1 \%$ in the past, $p<0.001)$. The prevalence of fatty liver in drinkers has increased in men (22.3\% in the past cohort, $36.6 \%$ in the current cohort; $\mathrm{p}<0.001)$ but not in women $(13.3 \%$ in the past cohort, $14.7 \%$ in the current cohort; $p=1.0$ ), while the prevalence of all fatty liver has increased in men and women (men: $24.0 \%$ in the past cohort, $36.2 \%$ in the current cohort, $p<0.001$; women: $9.3 \%$ in the past cohort, $12.8 \%$ in the current cohort, $p<0.001)$. Regarding metabolic abnormalities, the prevalence of hyperglycaemia increased from $25.4 \%$ to $43.0 \%$ in men with AFLD $(p<0.001)$ and from $25.1 \%$ to $39.1 \%$ in women with AFLD $(p=1.0)$. Conclusions AFLD currently tends to be accompanied by hyperglycaemia. The prevalence of fatty liver in drinkers increased in men, although alcoholic consumptions did not increase. We should pay attention to fatty liver combined with hyperglycaemia for individuals who consume alcohol today.

\section{INTRODUCTION}

The proportion of alcohol-attributable deaths among total deaths decreased slightly between $2010(5.6 \%)$ and $2016(5.3 \%)$, whereas the proportion of alcohol-attributable disabilityadjusted life years (DALYs) remained relatively stable $(5.1 \%$ of all DALYs in 2010 and
Summary box

What is already known about this subject?

- The prevalence of alcohol-related liver disease (ARLD) has continued to increase after 2000, although the volume of alcohol consumption did not increase. Alcoholic fatty liver disease (AFLD) has been recognised as a new ARLD phenotype.

What are the new findings?

- AFLD currently tends to be accompanied by hyperglycaemia.

How might it impact on clinical practice in the foreseeable future?

- We should pay attention to fatty liver combined with hyperglycaemia for individuals who consume alcohol today.

2016). ${ }^{1}$ Alcohol-related liver disease (ARLD), which refers to liver damage caused by excess alcohol intake, is the most common chronic liver disease worldwide. ${ }^{2}$ The burden of ARLD was about $40 \%$ of deaths associated with liver cirrhosis. ${ }^{2}$ While hepatitis C virusrelated mortality increased to 2.9 persons per 10 million per year, ARLD mortality increased to 4.4 persons per 10 million per year. ${ }^{3}$ Regarding treatment, medications for ARLD have not progressed, while the medication for virus hepatitis has been improved dramatically. Thus, ARLD has been recognised as an important liver disease.

In Japan, a nationwide survey for ARLD has been performed six times, ${ }^{4-8}$ and the prevalence of ARLD increased, along with the increase of alcohol consumption until 2000. In fact, the volume of alcohol consumption has increased since the 1960s-2000s. ${ }^{4-6}$ Interestingly, the prevalence of ARLD has continued to increase after 2000, although the volume of alcohol consumption did not increase after $2000 .^{4-6}$ 
Alcoholic fatty liver disease (AFLD) has been recognised as a new ARLD phenotype. AFLD has been thought to be increasing with the spread of metabolic syndrome. ${ }^{9}$ ARLD is a disease associated with malnutrition. Although ARLD was reported to be associated with undernutrition in the past, ${ }^{7}$ it was recently reported to be associated with overnutrition. In addition, the overall alcohol consumption volume has decreased to $90 \%$ of its peak, although it decreased throughout the peak volume. ${ }^{4-6}$ On the other hand, the social conditions regarding dietary intakes have been changed, and fast food availability, high fat content of foods and high sugar content of foods are increasing. These social conditions may contribute to the change in metabolic complications in patients with AFLD. Here we compare the metabolic complications in current AFLD with those of two decades ago.

\section{METHODS}

\section{Study population and design}

We previously performed a longitudinal cohort study, known as the non-alcoholic fatty liver disease (NAFLD) in the Gifu Area, Longitudinal Analysis (NAGALA) study, to reveal the impact of NAFLD on several types of chronic diseases. ${ }^{10}$ Patients who received health check-ups at Asahi University Hospital were invited to participate in the study and were excluded only when they were unwilling to participate.

In this study, we selected two cohorts separated by 20 years. The past cohort consisted of participants who underwent health check-ups between June 1994, when the centre was founded, and December 1997. The current cohort consisted of participants who underwent health check-ups from January 2014 to December 2017.

Participants with known liver disease were excluded from the study. ${ }^{11}$ Known liver disease was defined as positivity for hepatitis B antigen or hepatitis C antibody or a history of known viral, genetic, autoimmune or druginduced liver disease. ${ }^{12}$

\section{Data collection and measurements}

Details of the data collection and measurement methods were described previously. ${ }^{13}$ Briefly, we used a standardised self-administered questionnaire to acquire information about each participant's medical history and lifestyle factors, including smoking habits, alcoholic consumption and physical activity. ${ }^{10}{ }^{13}$ We estimated the mean ethanol intake per week using the data of amounts and types of alcoholic beverages consumed per week and divided the participants into three groups: non-alcoholic, $<210 \mathrm{~g}$ /week in men and $<140 \mathrm{~g} /$ week in women; intermediate, $210-420 \mathrm{~g} /$ week in men and $140-280 \mathrm{~g}$ /week in women; and alcoholic, $\geq 420 \mathrm{~g} /$ week in men and $\geq 280 \mathrm{~g} /$ week in women. ${ }^{13}$

Regarding exercise, if individuals participated in any kind of sports activity at least once a week on a regular basis, we categorised them as regular exercisers. ${ }^{4}$ We used the conventional criteria for Asian obesity (body mass index $\left.(\mathrm{BMI}) \geq 25 \mathrm{~kg} / \mathrm{m}^{2}\right) .{ }^{15} 16$ We defined the metabolic abnormality as follows: hyperglycaemia (fasting plasma glucose $>5.6 \mathrm{mmol} / \mathrm{L}$ ), hypertension (blood pressure $>130 / 85 \mathrm{~mm} \mathrm{Hg}$ ), lowhigh-densitylipoprotein (HDL) cholesterol levels (serum HDL cholesterol $<1.03 \mathrm{mmol} / \mathrm{L}$ in men and $<1.29 \mathrm{mmol} / \mathrm{L}$ in women), and hypertriglyceridemia (serum triglycerides $>1.70 \mathrm{mmol} / \mathrm{L}$ ). We defined the metabolic syndrome score as the presence of metabolic syndrome components (range 0-5) ${ }^{16}$ NAFLD fibrosis score was calculated using the formula described elsewhere. $^{17}$

\section{Definition of fatty liver, NAFLD and AFLD}

Fatty liver was diagnosed by the findings of abdominal ultrasonography performed by a trained technician. ${ }^{18} 19$ Fatty liver was diagnosed based on the findings of ultrasonography. Among the four known criteria, hepatorenal echo contrast and liver brightness are required for fatty liver. In addition, we categorised fatty liver into NAFLD and AFLD according to the volume of alcohol consumption as follows: NAFLD: $<210 \mathrm{~g} /$ week in men and $<140 \mathrm{~g} /$ week in women; and AFLD: $\geq 420 \mathrm{~g} /$ week in men and $\geq 280 \mathrm{~g} /$ week in women. ${ }^{20}$

\section{Statistical analysis}

We used two-sided test, and $p$ values of 0.05 or less were considered statistically significant. We analysed all data using SPSS software V.25. We divided the participants into men and women. Means or frequencies of variables were calculated, and continuous variables are presented as median (IQR). To assess the statistical significance of intergroup differences, we used the $\chi^{2}$ test for categorical variables, or the Wilcoxon signed-rank test for continuous variables since the latter did not follow a normal distribution.

\section{RESULTS}

The past cohort consisted of 7794 participants (5014 men and 2780 women), while the current cohort consisted of 20385 participants (11910 men and 8475 women). After the exclusion of participants with known liver disease, 7499 participants (4804 men and 2695 women) in the past cohort and 20029 participants (11676 men and 8353 women) in the current cohort were entered to this study (figure 1).

Among the male subjects, the prevalence of alcoholics in the current cohort was lower than that in the past cohort ( $5.9 \%$ vs $4.7 \%$, respectively; $\mathrm{p}=0.002$ ), while that of the non-alcoholic group was higher in the current cohort than in the past cohort $(78.8 \%$ vs $83.4 \%$, respectively; $\mathrm{p}<0.001)$. On the other hand, among women, the prevalence of alcoholics was higher in the current group than in the past group ( $1.1 \%$ vs $1.9 \%$, respectively; $\mathrm{p}=0.009)$; however, the majority did not change in the non-alcoholic group ( $96.1 \%$ vs $95.3 \%$, respectively; $\mathrm{p}=0.086$ ).

Next, we investigated the characteristics of the participants according to alcohol consumption. The median age of the male drinkers increased from 48 (39.5-55.0) 


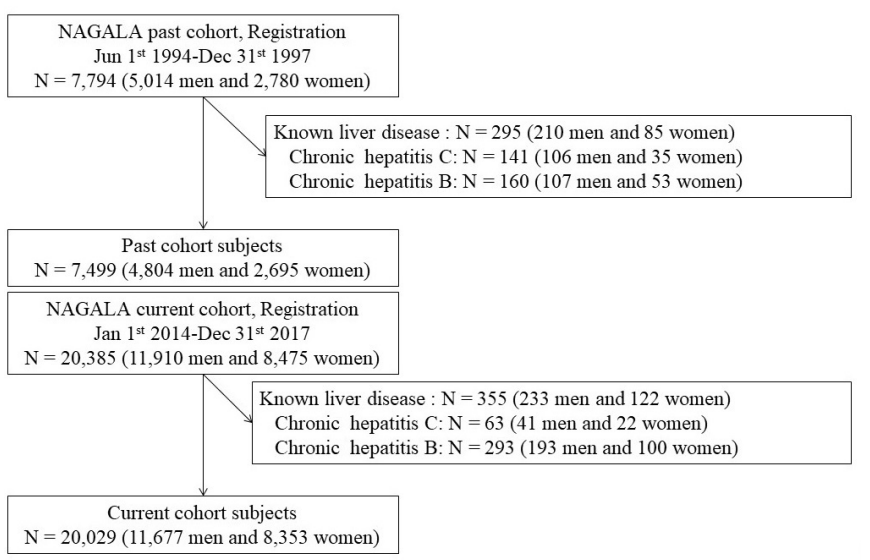

Figure 1 Flowchart of inclusion and exclusion criteria. NAGALA, NAFLD in Gifu area, longitudinal analysis.

years old to $54(47.5-59.0)$ years in the current group $(\mathrm{p}<0.001$, table 1$)$. On the other hand, those of female drinkers were not significantly different between cohorts (46 (38.0-53.5) years old in the past cohort and 47 (40.052.0 ) years old in the current cohort, $\mathrm{p}=0.55$; table 1 ). The proportion of male drinkers in their $30 \mathrm{~s}$ and $40 \mathrm{~s}$ significantly decreased (30s: $5.5 \%$ in the past cohort and $2.2 \%$ in the current cohort, $\mathrm{p}<0.001 ; 40 \mathrm{~s}: 6.2 \%$ in the past cohort and $4.3 \%$ in the current cohort, $\mathrm{p}=0.005$; online supplementary table 1$)$. On the other hand, the proportion of female drinkers in their $30 \mathrm{~s}, 40 \mathrm{~s}, 50 \mathrm{~s}$, and $60 \mathrm{~s}$ increased over the two decades (30s: $1.0 \%$ in the past cohort and $1.9 \%$ in the current cohort, $\mathrm{p}=0.111 ; 40 \mathrm{~s}$ : $1.2 \%$ in the past cohort and $2.1 \%$ in the current cohort, $\mathrm{p}=0.047 ; 50 \mathrm{~s}: 1.3 \%$ in the past cohort and $1.8 \%$ in the current cohort, $\mathrm{p}=0.257 ; 60 \mathrm{~s}: 0 \%$ in the past cohort and $1.9 \%$ in the current cohort, $\mathrm{p}=0.014$; online supplementary table 1).

The prevalence of fatty liver increased in both men and women (men: $24.0 \%$ in the past cohort and $36.2 \%$ in the current cohort, $\mathrm{p}<0.001$; women: $9.3 \%$ in the past cohort and $12.8 \%$ in the current cohort, $\mathrm{p}<0.001)$. In men, the prevalence of AFLD tended to be higher than that in the past $(22.3 \%$ vs $36.6 \%$, respectively; $\mathrm{p}=0.077)$; in women, the prevalence of AFLD in the past and current cohorts were similar $(13.3 \%$ vs $14.7 \%$, respectively; $\mathrm{p}=1.0$; table 1). On the other hand, the prevalence of NAFLD has also increased in both men and women (men: $24.7 \%$ in the past cohort vs $36.6 \%$ in the current cohort, $\mathrm{p}<0.001$; women: $9.1 \%$ in the past cohort vs $12.9 \%$ in the current cohort, $\mathrm{p}<0.001$; online supplementary table 2 ).

Regarding the age-specific prevalence of AFLD (online supplementary table 1 ), men in their 40 s and 50s significantly increased (30s: $18.4 \%$ in the past cohort and $32.5 \%$ in the current cohort, $\mathrm{p}=0.021 ; 40 \mathrm{~s}: 6.2 \%$ in the past cohort and $4.3 \%$ in the current cohort, $\mathrm{p}<0.001$ ). In the same way, that of women with AFLD in their 50s increased over the two decades $14.5 \%$ in the past cohort and $19.5 \%$ in the current cohort, $\mathrm{p}=0.002$; online supplementary table 1 ).
The median age of the participants with AFLD increased from $46.5(38.8-68.5)$ years to $50(44-55)$ years in men $(\mathrm{p}<0.001)$ but was not significantly different in women (46.5 (38.8-68.5) years in the past cohort, 50 $(44.0-55.0)$ years in the current cohort, $\mathrm{p}=0.73$; table 2$)$. Regarding metabolic abnormalities, that of hyperglycaemia increased from $25.4 \%$ to $43.0 \%$ in men $(p<0.001)$ and from $25.1 \%$ to $39.1 \%$ in women $(p=1.0)$. The prevalence of hypertriglyceridemia significantly decreased from $68.3 \%$ to $34.0 \%$ in men $(p<0.001)$; on the other hand, that in women was not significantly different between cohorts $(25.0 \%$ in the past cohort and $21.7 \%$ in the current cohort, $\mathrm{p}=0.859$ ).

\section{DISCUSSION}

Here we clearly presented that alcohol consumption and the proportion of intermediate alcohol consumption in men decreased. On the other hand, alcohol consumption in women tended to decrease; however, the proportion of alcoholic participants increased over the two decades. Nevertheless, the proportion of men with AFLD in the current cohort tended to increase. In addition, the presence of fatty liver significantly increased in both men and women; likewise, that of NAFLD significantly increased in both men and women. Contrary to our initial expectations, the prevalence of obesity increased among the overall participants, whereas that in the participants with AFLD did not differ between the past and current cohorts. An increase in non-obese diabetic patients is a common problem in East Asia. ${ }^{21}$ Actually, the prevalence of type 2 diabetes in East Asia has been increasing explosively, and it is expected that half of the world's diabetic patients will be East Asians. ${ }^{22}$ In Japan, the Westernisation of lifestyles began at around 1955, which changed old Japanese lifestyles and increased the prevalence of type 2 diabetes. Therefore, discussion of the change in characteristics of Japanese people can help predict the future in East Asia.

The volume of alcohol consumption decreased in this study. In particular, the proportion of alcoholic men in their $30 \mathrm{~s}$ and $40 \mathrm{~s}$ decreased, as did the prevalence of AFLD. On the other hand, the proportions of alcoholic women in their 30s, 40s, 50s and 60s decreased; however, there was no significant difference in the prevalence of AFLD. Among the participants with AFLD, the volume of alcohol consumption did not change in men but decreased in women.

Regarding metabolic abnormalities of alcoholic participants, the prevalence of hypertension and hyperglycaemia increased in both men and women, whereas those of hypertriglyceridemia and low HDL cholesterol levels decreased. On the other hand, BMI significantly decreased in men and did not change in women.

Besides excessive alcohol intake, metabolic abnormalities exacerbate liver cirrhosis in patients with AFLD. ${ }^{7}$ On the other hand, alcoholic liver cirrhosis could develop in diabetic patients due to lower alcohol intake than 


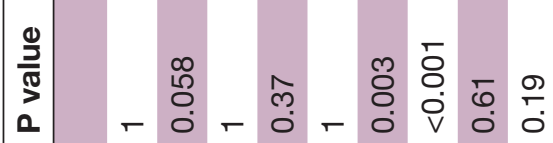

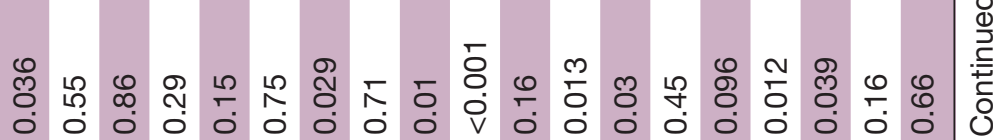

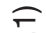

O

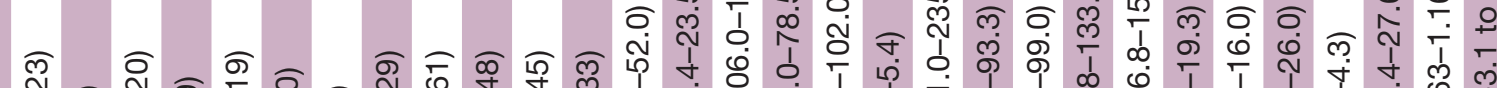

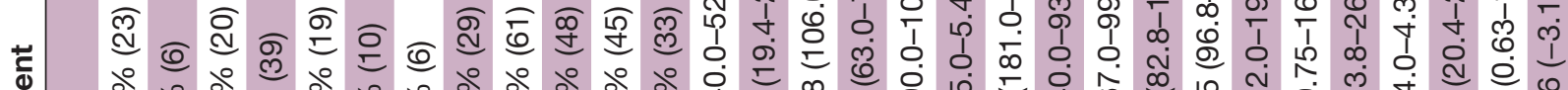
ఏ U

章

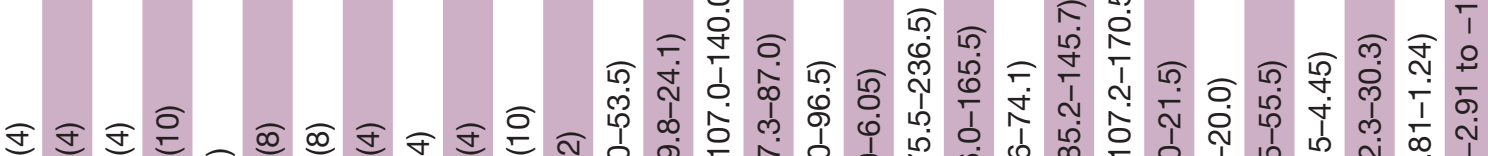

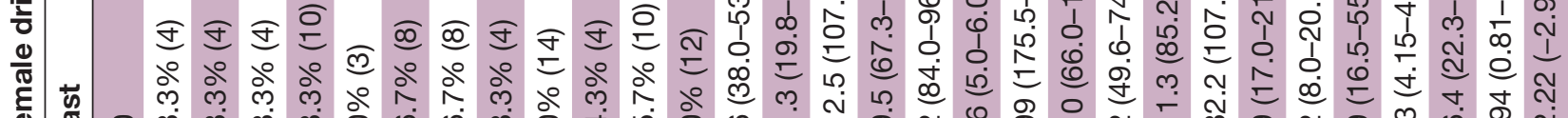
㐫

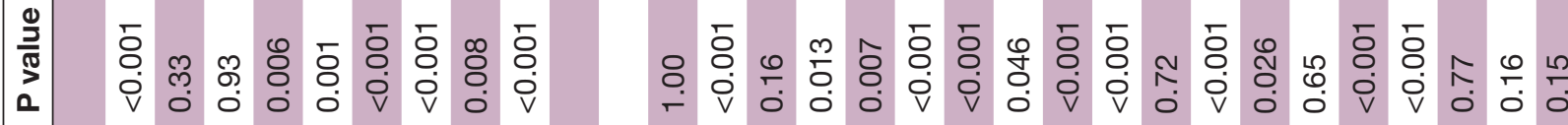

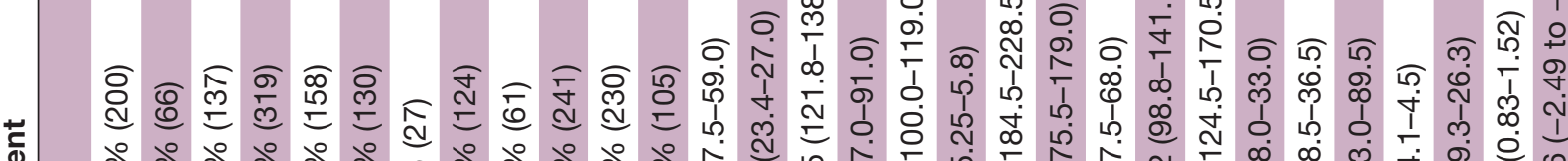

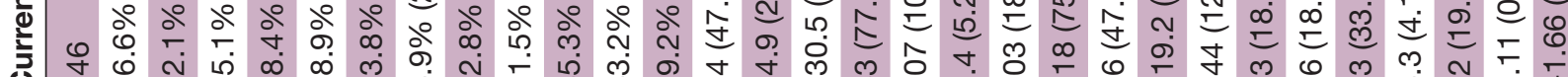
U 
non-diabetic patients. ${ }^{8}$ Impaired glucose tolerance is known to be associated with steatosis grade in patients with chronic liver disease. ${ }^{8} 19$ Thereafter, abnormal glucose metabolism is considered a risk factor for alcoholic liver disease (ALD), including AFLD. In line with these contexts, our study findings indicated that the prevalence of hyperglycaemia increased recently in individuals with AFLD; however, the volume of alcoholic consumption has not changed.

Emaciation used to be a problem in patients with $\mathrm{ALD}^{4-6}$; however, obesity is thought to be a new health threat for ALD. ${ }^{7}$ Our study findings indicated that the prevalence of obesity among individuals with AFLD did not increase. A possible explanation for this is decreased muscle mass. Several previous studies reported that muscle mass was not different or slightly increased until the 30s and started to decline around 45 or 50 years old. ${ }^{23}$ The participants with AFLD in the current cohort were older than those in the past. Therefore, decreased muscle mass, that is, sarcopenia, might lead to decreased body weight.

Thereafter, alcoholic consumption could exacerbate liver cirrhosis, even in patients with non-alcoholic steatohepatitis (NASH). NASH is now distinguished from ALD. Regarding the disease concept, men who had chronic hepatitis or fatty liver but consumed $<210 \mathrm{~g} /$ week of alcohol are not diagnosed with NAFLD or AFLD. ${ }^{13}$ In the same way, women who had chronic hepatitis or fatty liver but consumed $<140 \mathrm{~g}$ /week of alcohol are not diagnosed with either. ${ }^{13}$ In this study, we classified men who consumed 210-420 g/week of alcohol or women who consumed 140-280 g/week of alcohol as the intermediate group. We should manage the chronic hepatitis and fatty liver of the individuals of the intermediate group.

The strengths of our study include its use of the same standardised diagnosis of fatty liver ${ }^{10}$ and the standardised questionnaire of lifestyle factors, and its relatively large population-based longitudinal research. Our study also has some limitations. First, all patients were sampled from a health check-up centre. There may be bias in the sampling method. The subjects consisted of 3924 costly individuals, which might include the difference of willingess for health check-up programmes between the current cohort and the past cohort. However, we previously reported that the body weight in our study sample was well in accord with those reported in a larger populationbased national nutrition survey done in Japan National Nutrition Survey 1990-1994 ${ }^{25}$ or 2014-2017 (https:// www.mhlw.go.jp/bunya/kenkou/kenkou_eiyou_chousa. html). The prevalence of hepatitis $\mathrm{C}$ virus (HCV) or hepatitis $\mathrm{B}$ virus (HBV) decreased in the current cohort compared with the past cohort. In Japan, the number of HBV or HCV has been reduced by the comprehensive control measures for hepatitis promoted by Ministry of Health, Labour and Welfare. ${ }^{26-28}$ However, we cannot exclude the possibility that our sample contained more health-conscious people than the general population in Japan. The prevalence of drinkers in our study sample 


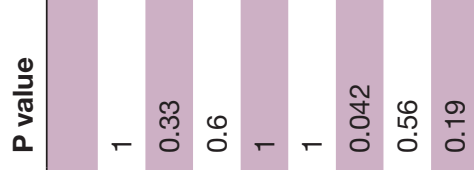

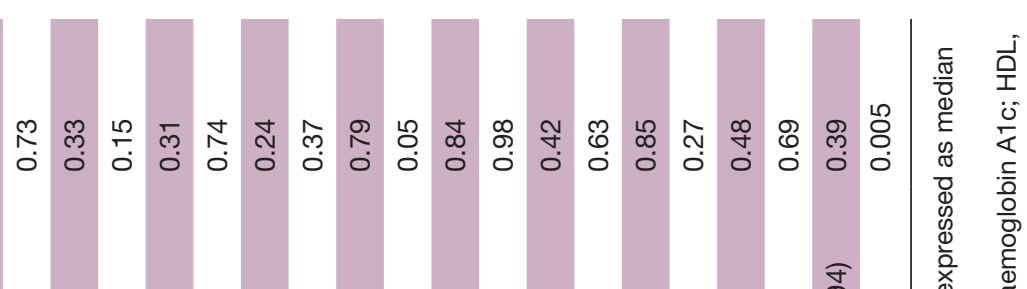

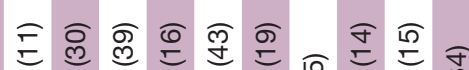


was lower than those reported in Japan National Nutrition Survey 1995 or 2015 (https://www.mhlw.go.jp/ bunya/kenkou/kenkou_eiyou_chousa.html) (online supplementary table 3 ). Second, we presented the agespecific prevalence of AFLD, but the denominator of all age subgroups in women of the past cohort was less than 15 , and all except one subgroup in men were less than 100 . We could not exclude the possible overestimation or underestimation due to the low denominator of the age subgroups. Third, the generalisability of our study in non-Japanese populations is low. Fourth, abdominal ultrasonography for evaluating fatty liver has limited diagnostic accuracy in cases of mild hepatic steatosis. ${ }^{29}$ However, we assessed fatty liver based on standardised diagnostic criteria and could have evaluated a certain level of fatty liver. ${ }^{18}$ Fifth, we had a limited ability to examine different levels of physical activity. If we could evaluate the frequency and intensity of exercise, a more accurate analysis would be possible.

In conclusion, AFLD currently tends to be accompanied by hyperglycaemia. The prevalence of fatty liver in drinkers increased in men, although alcoholic consumptions did not increase. These trends can help predict the future in East Asia. We should pay attention to fatty liver combined with hyperglycaemia for individuals who consume alcohol today.

\section{Strengths and limitations}

The study clearly indicated that AFLD currently tends to be accompanied by hyperglycaemia over two decades. This paper is the first report of metabolic complications of AFLD in a single facility comparing the current cohort with the past cohort. The limitation of the study is that all patients were sampled from a health check-up centre. There may be bias in the sampling method. However, the body weights in our study sample were well in accord with those reported in a larger population-based national nutrition survey done in Japan National Nutrition Survey 1990-1994 or 2014-2017.

Acknowledgements All authors thank the medical staff of Asahi University Hospital. We would like to thank Editage (www.editage.com) for English language editing.

Contributors All authors thank the medical staff of Asahi University Hospital and Editage (www.editage.com) for English language editing.

Funding The authors have not declared a specific grant for this research from any funding agency in the public, commercial or not-for-profit sectors.

Competing interests $\mathrm{MH}$ and MF received grants, honoraria, and research support from AstraZeneca plc, Astellas Pharma Inc, Nippon Boehringer Ingelheim Co, Ltd, Daiichi Sankyo Co, Ltd, Eli Lilly Japan KK, Kyowa Hakko Kirin Company Ltd, Kissei Pharmaceutical Co, Ltd, MSD KK, Kowa Company, Ltd, Mitsubishi Tanabe Pharma Corporation, Novo Nordisk Pharma Ltd, Sanwa Kagaku Kenkyusho Co, Ltd, Sanofi KK, Ono Pharmaceutical Co, Ltd, Taisho Toyama Pharmaceutical Co, Ltd, and Takeda Pharmaceutical $\mathrm{Co}$, Ltd. The sponsors were not involved in the study design; data collection, analysis, and interpretation; writing of this manuscript; or the decision to submit the article for publication. The authors, their immediate families, and any research foundations with which they are affiliated have not received any financial payments or other benefits from any commercial entity related to the subject of this article. The authors declare that, although they are affiliated with a department that is supported financially by a pharmaceutical company, they received no funding for this study, which does not alter their adherence to all the journal policies on sharing data and materials. The other authors have nothing to disclose.

Patient consent for publication Not required.

Ethics approval The current version of NAFLD in the Gifu Area, Longitudinal Analysis was approved by the medical ethics committee of Asahi University Hospital; the study design was opt-out sampling (ID 2018-09-01).

Provenance and peer review Not commissioned; externally peer reviewed.

Data availability statement The data-sets of the current study are available from the corresponding author on reasonable request.

Open access This is an open access article distributed in accordance with the Creative Commons Attribution Non Commercial (CC BY-NC 4.0) license, which permits others to distribute, remix, adapt, build upon this work non-commercially, and license their derivative works on different terms, provided the original work is properly cited, appropriate credit is given, any changes made indicated, and the use is non-commercial. See: http://creativecommons.org/licenses/by-nc/4.0/.

\section{ORCID iDs}

Masahide Hamaguchi http://orcid.org/0000-0002-8651-4445

Takuro Okamura http://orcid.org/0000-0001-7269-1697

\section{REFERENCES}

1 World Health Organization. Global status report on alcohol and health 2018, n.d. Available: http://apps.who.int/iris/bitstream/handle/ 10665/274603/9789241565639-eng.pdf?ua=1

2 Kim WR, Brown RS, Terrault NA, et al. Burden of liver disease in the United States: summary of a workshop. Hepatology 2002;36:227-42.

3 Paula H, Asrani SK, Boetticher NC, et al. Alcoholic liver disease-related mortality in the United States: 1980-2003. Am J Gastroenterol 2010;105:1782-7.

4 Takeuchi J, Okudaira M, Takada A, et al. [The incidence of alcoholic liver disease in Japan (1976-1985)]. Nihon Shokakibyo Gakkai Zasshi 1987;84:1623-30.

5 Takada A, Tsutsumi M. National survey of alcoholic liver disease in Japan (1968-91). J Gastroenterol Hepatol 1995;10:509-16.

6 Horie Y, Yamagishi Y, Kato S, et al. [Alcoholic liver diseases and hepatitis virus $\mathrm{C}$ in Japan]. Nihon Arukoru Yakubutsu Igakkai Zasshi 2006;41:424-30.

7 Horie $\mathrm{Y}$, Yamagishi Y, Ebinuma H, et al. Obesity, type 2 diabetes, age, and female gender: significant risk factors in the development of alcoholic liver cirrhosis. Hepatol Int 2013;7:280-5.

8 Kikuchi M, Horie Y, Ebinuma $\mathrm{H}$, et al. Alcoholic Liver Cirrhosis and Significant Risk Factors for the Development of Alcohol-related Hepatocellular Carcinoma--Japan, 2012. Nihon Arukoru Yakubutsu Igakkai Zasshi 2015;50:222-34.

9 Styskel B, Natarajan Y, Kanwal F. Nutrition in alcoholic liver disease: an update. Clin Liver Dis 2019;23:99-114.

10 Hamaguchi M, Kojima T, Takeda N, et al. The metabolic syndrome as a predictor of nonalcoholic fatty liver disease. Ann Intern Med 2005;143:722-8.

11 Fukuda Y, Hashimoto Y, Hamaguchi M, et al. Triglycerides to highdensity lipoprotein cholesterol ratio is an independent predictor of incident fatty liver; a population-based cohort study. Liver Int 2016;36:713-20.

12 McCullough AJ. The clinical features, diagnosis and natural history of nonalcoholic fatty liver disease. Clin Liver Dis 2004;8:521-33.

13 Hashimoto Y, Hamaguchi M, Kojima T, et al. Modest alcohol consumption reduces the incidence of fatty liver in men: a population-based large-scale cohort study. J Gastroenterol Hepatol 2015;30:546-52.

14 Ryu S, Chang Y, Kim D-I, et al. Gamma-Glutamyltransferase as a predictor of chronic kidney disease in nonhypertensive and nondiabetic Korean men. Clin Chem 2007;53:71-7.

15 Fukuda T, Hamaguchi M, Kojima T, et al. The impact of non-alcoholic fatty liver disease on incident type 2 diabetes mellitus in nonoverweight individuals. Liver Int 2016;36:275-83.

16 Hashimoto Y, Tanaka M, Kimura T, et al. Hemoglobin concentration and incident metabolic syndrome: a population-based large-scale cohort study. Endocrine 2015;50:390-6.

17 Sumida $\mathrm{Y}$, Yoneda M, Hyogo $\mathrm{H}$, et al. Validation of the FIB4 index in a Japanese nonalcoholic fatty liver disease population. BMC Gastroenterol 2012;12:2.

18 Hamaguchi M, Kojima T, Itoh Y, et al. The severity of ultrasonographic findings in nonalcoholic fatty liver disease reflects 
the metabolic syndrome and visceral fat accumulation. $A m \mathrm{~J}$ Gastroenterol 2007;102:2708-15.

19 Hamaguchi M, Takeda N, Kojima T, et al. Identification of individuals with non-alcoholic fatty liver disease by the diagnostic criteria for the metabolic syndrome. World J Gastroenterol 2012;18:1508-16.

20 Chitturi S, Farrell GC, Hashimoto E, et al. Non-Alcoholic fatty liver disease in the Asia-Pacific region: definitions and overview of proposed guidelines. J Gastroenterol Hepatol 2007;22:778-87.

21 Ma RCW, Chan JCN. Type 2 diabetes in East Asians: similarities and differences with populations in Europe and the United States. Ann N Y Acad Sci 2013;1281:64-91.

22 Yuan H, Li X, Wan G, et al. Type 2 diabetes epidemic in East Asia: a 35-year systematic trend analysis. Oncotarget 2018;9:6718-27.

23 Janssen I, Heymsfield SB, Wang ZM, et al. Skeletal muscle mass and distribution in 468 men and women aged 18-88 yr. J Appl Physiol 2000;89:81-8.

24 Melton LJ, Khosla S, Crowson CS, et al. Epidemiology of sarcopenia. J Am Geriatr Soc 2000;48:S10-13.
25 Yoshiike N, Matsumura Y, Zaman MM, et al. Descriptive epidemiology of body mass index in Japanese adults in a representative sample from the National nutrition survey 1990 1994. Int J Obes 1998;22:684-7.

26 Shimoyama R, Sekiguchi S. [Basic and clinical aspects of hepatitis virus carriers]. Hokkaido Igaku Zasshi 1996;71:427-48.

27 Tanaka J, Kumagai J, Katayama K, et al. Sex- and age-specific carriers of hepatitis $B$ and $C$ viruses in Japan estimated by the prevalence in the $3,485,648$ first-time blood donors during 1995 2000. Intervirology 2004;47:32-40.

28 Tanaka J, Koyama T, Mizui M, et al. Total numbers of undiagnosed carriers of hepatitis $\mathrm{C}$ and $\mathrm{B}$ viruses in Japan estimated by ageand area-specific prevalence on the National scale. Intervirology 2011:54:185-95.

29 Lee SS, Park SH, Kim HJ, et al. Non-Invasive assessment of hepatic steatosis: prospective comparison of the accuracy of imaging examinations. J Hepatol 2010;52:579-85. 